\title{
An environmental scan of policies in support of chronic disease self-management in Canada
}

\section{Liddy, MD (1, 2); K. Mill, BSc (1)}

This article has been peer reviewed.

\begin{abstract}
Introduction: The evidence supporting chronic disease self-management warrants further attention. Our aim was to identify existing policies, strategies and frameworks that support self-management initiatives.
\end{abstract}

Methods: This descriptive study was conducted as an environmental scan, consisting of an Internet search of government and other publicly available websites, and interviews with jurisdictional representatives identified through the Health Council of Canada and academic networking.

Results: We interviewed 16 representatives from all provinces and territories in Canada and found 30 publicly available and relevant provincial and national documents. Most provinces and territories have policies that incorporate aspects of chronic disease selfmanagement. Alberta and British Columbia have the most detailed policies. Both feature primary care prominently and are not disease specific. Both also have provincial level implementation of chronic disease self-management programming. Canada's northern territories all lacked specific policies supporting chronic disease self-management despite a significant burden of disease.

Conclusion: Engaging patients in self-management of their chronic diseases is important and effective. Although most provinces and territories have policies that incorporate aspects of chronic disease self-management, they were often embedded within other initiatives and/or policy documents framed around specific diseases or populations. This approach could limit the potential reach and effect of self-management.

Keywords: chronic disease self-management, self-management support, health policy, primary care, environmental scan

\section{Introduction}

Chronic disease is Canada's most prominent health care problem, costing more than $\$ 80$ billion each year ${ }^{1,2}$ and causing increased use of emergency departments, extended hospital stays, reduced quality of life and increased mortality rates. ${ }^{3-10}$ Improving the quality of care for people with chronic diseases is complex, ${ }^{11}$ requiring timely diagnosis and treatment, access to primary and specialist care and a focus on selfmanagement tasks and decisions. ${ }^{12,13}$
Supporting people in self-management has been shown to be effective at improving outcomes and has been promoted across the widest array of conditions and populations. ${ }^{14-20}$ Self-management support (SMS) focuses on the individuals and their families by using collaborative goal setting and a variety of self-efficacy strategies. ${ }^{16}$ These strategies enable patients, together with their health care providers, to medically manage their illnesses more effectively, carry out normal roles and activities and manage the emotional impact of their illnesses. ${ }^{15}$ Adams et al. ${ }^{21}$ further this definition by highlighting what health care providers can do through "the systematic provision of education and supportive interventions by health care staff, $21, \mathrm{p} 57$ to increase patients' skills and confidence in managing their health problems, including regular assessment of progress and problems, goal setting and support in problemsolving.

There is much interest in implementing SMS programs in Canada. However, many programs are being implemented in isolation, often by disease-specific organizations or local public health or communitybased organizations. ${ }^{22}$ But while the patients and their communities, health providers and the health care delivery system are certainly linchpins in the success of chronic disease support and care, federal, provincial and territorial governments have major roles to play because they set and implement public policy for health and health care across Canada.

While there is some mention of the importance of self-care and self-management in national strategies, such as healthy aging $^{23}$ and the Canadian Diabetes strategy, ${ }^{24}$ little is known about provincial and territorial government policy directions associated with SMS, despite that these governments are responsible for health and health care within their jurisdictions.

As part of a broader project on chronic disease care and self-management conducted with the Health Council of Canada (HCC), ${ }^{25}$ we performed an environmental scan to identify provincial and territorial

\section{Author references:}

1. Bruyère Research Institute, C.T. Lamont Primary Health Care Research Centre, Ottawa, Ontario, Canada

2. University of Ottawa, Department of Family Medicine, Ottawa, Ontario, Canada

Correspondence: Clare Liddy, Bruyère Research Institute, 43 Bruyère St., Ottawa, ON K1N 5C8; Tel.: 613-562-6262 ext. 1326; Fax: 613-562-6099; Email: cliddy@bruyere.org 
government strategic policy documents that support patient self-management. ${ }^{26}$ The HCC is an independent, not-for-profit organization established by the country's first ministers in 2003 to monitor the health care system within the context of the Health Accords. The HCC has focused some of its attention on the prevention and management of chronic conditions to encourage discussion of the changes to public policy, health care management and health services delivery required to improve health outcomes for all Canadians. $^{27}$

The intent of this report is to increase awareness of provincial activities and policy directions to allow jurisdictions to build on emerging trends across the country.

\section{Methods}

We conducted the environmental scan of SMS and chronic disease care in three phases: (1) an online scan using the Google search engine to identify publicly available policies that support or influence SMS initiatives; (2) interviews with jurisdictional representatives of the HCC to gain an inside perspective on existing policies and strategies and future plans related to SMS; (3) a second online scan based on interview findings.

The aim of the first online scan was to identify publicly available policy documents at the provincial and territorial level. We defined policy as any course of action or broad direction endorsed by a body of authority in government and included frameworks, strategies, action plans and official priority documents. ${ }^{28}$

Three people from our research team scanned online literature and websites from each of the provinces and territories in September 2011 to identify policies, legislation, strategies and frameworks that discussed or focused on SMS and programs or their implementation. Keywords used in the search were "self-management," "self-care," “self-management support," "chronic conditions," " "policy,” "action plan," “'framework," “strategy”, and "initiative." Relevant findings were organized in a database using Microsoft
Excel version 12 (2007; Redmond, WA, US), tracking the year and details of each initiative.

Next, for a more in-depth and accurate view of existing policies, we interviewed individuals involved in policy in the ministries of health. Jurisdictional representatives from all provinces and territories, with the exception of Quebec, were identified and invited by email to participate in a 30-minute telephone interview through the network of the HCC. At the time, Quebec was not in a formal partnership with the HCC so we identified our Quebec participant through academic networking. All the jurisdictional representatives invited agreed to participate and granted informed consent. The interview process was approved by the Ottawa Hospital Research Ethics Board.

The interview guide used for these semistructured interviews is available from the authors on request. The principal investigator (CL) or the research assistant (KM) conducted the interviews between September and October 2011, with the Quebec interview conducted in May 2012. Interviews were recorded and transcribed by the research assistant. Copies of the interview transcripts were sent to each interviewee for approval to increase the trustworthiness of the results.

The third step of the study, which took place in July 2012, consisted of a focused online scan to identify newly released or updated policy documents that had been identified by the interviewees as forthcoming. The iterative analysis used examples of other policy scans for guidance. ${ }^{29-31}$ Based on the work by Dixon-Woods et al. $^{32}$ we used a descriptive narrative approach with thematic analysis. This approach has been identified as appropriate for reviews that focus on policy. ${ }^{32}$ Two members of the research team reviewed the policy documents and the interview transcripts to identify themes. Several team meetings were held during the analysis phase to discuss findings and come to an agreement upon key themes. $^{32}$

\section{Results}

Through our Internet scan and interviews with 16 representatives from all provinces and territories in Canada, we learned that most provinces and territories have a policy, framework or strategy that incorporates aspects of chronic disease management. However, they vary significantly in terms of number of available policy documents that explicitly acknowledge the role of self-management (see Table 1). Our online scan to identify policies that support or influence SMS initiatives found 30 publicly available and relevant provincial and national documents.

Most provinces have implemented SMS programs, the most common one being the Stanford Chronic Disease SelfManagement Program (see Table 2), although these are often run through small-scale community organizations or the local health regions. Of all the provinces, Alberta and British Columbia have the most detailed policies supporting patient self-management. They offer their widely available self-management programs mainly through provincial health organizations (as opposed to diseasespecific and or grassroots community groups). These programs focus on patient-centred care and include primary health care and primary care.

For example, Alberta has an overarching vision for the future of health care, called Vision 2020, ${ }^{33}$ that focuses on the needs of the patient. In addition, the development of its model of chronic disease management care and the launch of integrated community-based programming across the province promotes a well-rounded approach to supporting patients with chronic conditions. SMS is one of the main pillars of the model and programming. The Stanford Chronic Disease SelfManagement Program is now offered across the province through Alberta Health Services as the Better Choices, Better Health program. The program is a component of integrated communitybased programming, and patients can be referred to it by their physicians or staff from one of the other integrated programs. Other programs offered under the umbrella of integrated community-based 


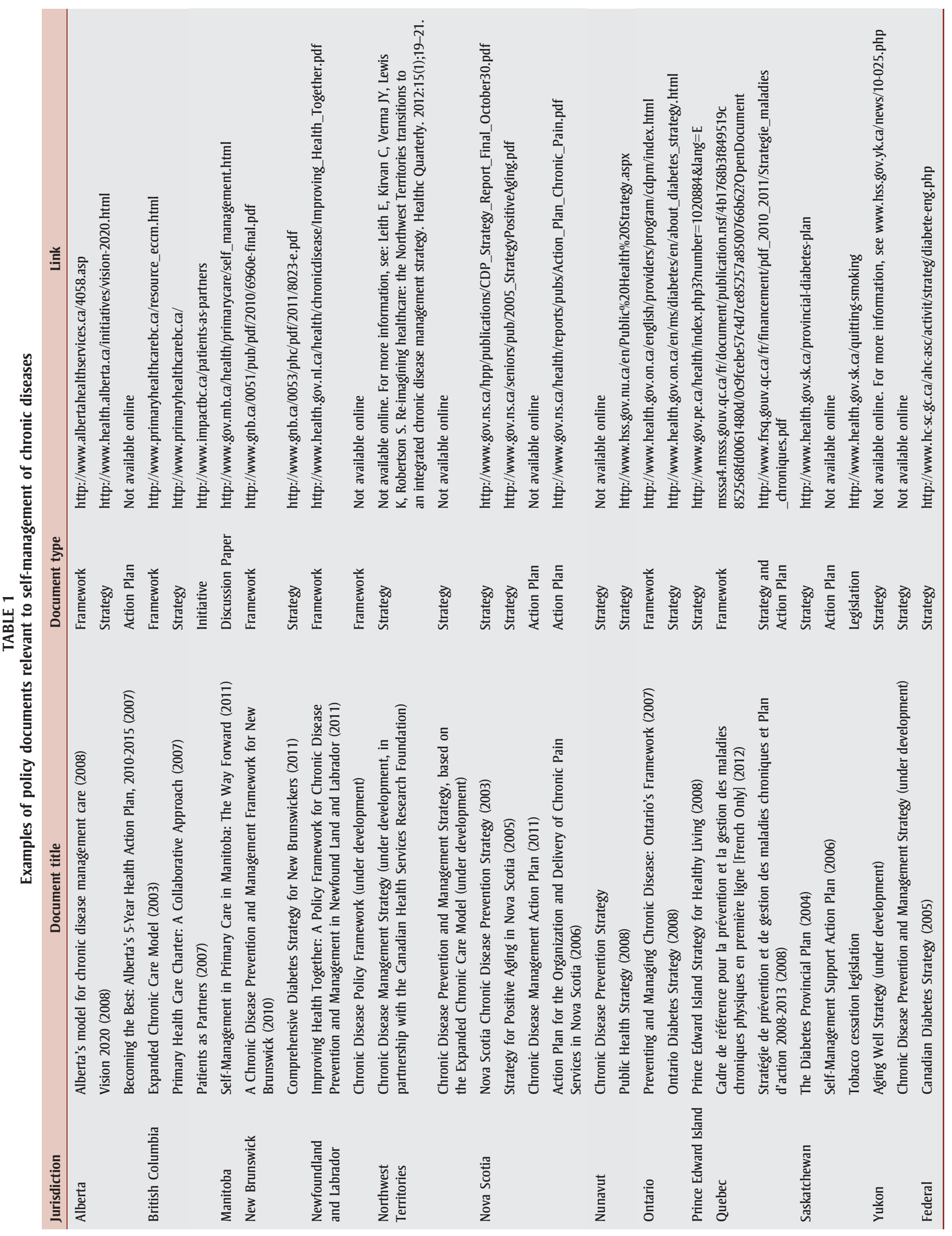




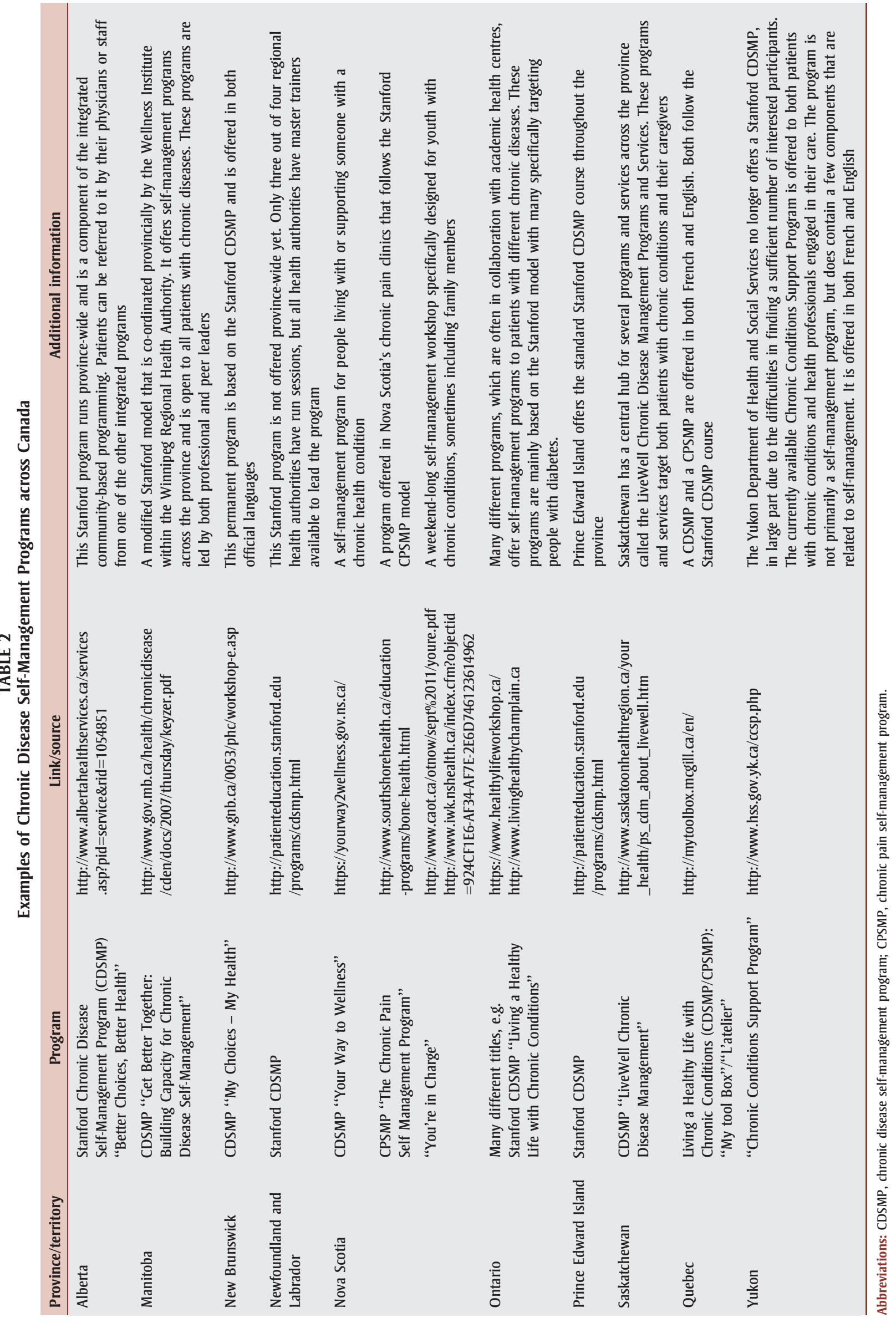


programming include supervised exercise programs and nutrition information through either a dietician or a group workshop. Primary Care Networks in Alberta also strongly encourages selfmanagement. The networks play a large role in the integrated community-based programming because of their ability to enhance care co-ordination and collaboration through shared care among the appropriate providers.

Similarly, self-management is identified in the mission, vision and goals of the British Columbia Ministry of Health. The ministry initiative, Patients as Partners, part of the 2007 Primary Health Charter, ${ }^{34}$ specifically addresses self-management implementation and evaluation in asking primary health care providers and organizations to develop additional ways to support the central role of patients as partners in their own care. The province offers many SMS programs, including Chronic Disease Self-Management; Online Chronic Disease Self-Management; Arthritis/Fibromyalgia Self-Management; Chronic Pain Self-Management; Diabetes Self-Management; Active Choices; A Matter of Balance: Managing Concerns about Falls; Bounce Back: Reclaim Your Health; InterCultural Online Health Network; Patient Voices Network's Peer Coaching; Dietician Services at HealthLink BC; and QuitNow Services.

Manitoba has also recently released a discussion paper specifically targeting self-management in primary care.

\section{Frameworks}

Many of the other provinces have chronic disease management and prevention frameworks that include self-management as a core component. For example, Ontario, New Brunswick and Quebec have aligned their Chronic Disease Management and Prevention (CDMP) Frameworks, based on the Expanded Chronic Care Model, ${ }^{34,35}$ to build future strategies and policies for the prevention and management of chronic diseases. The Expanded Chronic Care Model itself builds on the wellknown Chronic Care Model (CCM), ${ }^{36}$ which has been shown to enhance the delivery and quality of care and control health care costs. ${ }^{14,19,37}$ The Expanded Chronic Care Model is more suited to the Canadian health care environment because it more effectively integrates health promotion and prevention in both the health system and communities.

Newfoundland and Labrador has also adopted a Chronic Disease Policy Framework that includes six policy statements, one which focuses on self-management. $^{38}$ It has eight priority areas: arthritis, cancer, chronic pain, diabetes, heart disease, lung disease, kidney disease and stroke. It covers all four regional health authorities in the province.

\section{Strategies}

The Unit for Population Health and Chronic Disease Prevention at Dalhousie University, in collaboration with the Nova Scotia Department of Health, developed the Nova Scotia Chronic Disease Prevention Strategy in 2003; however, it does not explicitly emphasize self-management. The Strategy for Positive Aging in Nova Scotia, published in 2005, does speak of the importance of self-management for seniors.

\section{Disease-specific policies with a focus on self-management}

Many of the provinces have policies that focus on disease-specific conditions, such as diabetes, arthritis, stroke and chronic obstructive pulmonary disease. For example, The Ontario Diabetes Strategy, launched in 2008, emphasizes patients' self-management as an important component. Under this strategy, funding was allocated to cover a four-year plan to execute a multidimensional approach to diabetes care that addresses the growing needs of the Ontario population. The Ontario Diabetes Strategy appears to be the leading strategy in Ontario in terms of incorporating self-management. However, the interviewed experts in the field expressed the belief that there is a need to go beyond a disease-specific strategy toward a general policy that addresses self-management of chronic diseases as a whole, especially in patients with multimorbidities.
Saskatchewan's Provincial Diabetes Plan, released in February 2004, emphasizes the role of self-management. The Saskatchewan Ministry of Health and local health authorities have also set in place guidelines that mandate the delivery of SMS.

In Prince Edward Island, self-management of specific chronic diseases is also addressed in some programs, such as those for diabetes and arthritis. The province has also been piloting programs for chronic obstructive pulmonary disease, hypertension and weight management that include self-management components. Prince Edward Island does not have a specific policy document to support self-management of chronic diseases in general. Instead, it offers education and training for health care providers that incorporates self-management principles.

\section{Lack of policies, frameworks, strategies in the North}

\section{Nunavut}

Our policy scan, further supported by our interview with a local expert in Nunavut, revealed that the territory does not have policy documents or strategies that specifically address the issue of self-management for patients with chronic diseases. In addition, there are currently no active selfmanagement programs to support either patients or health professionals in Nunavut.

\section{Northwest Territories}

There are no policies in place in the Northwest Territories that specifically support the design and implementation of self-management programs for patients with chronic diseases, although a chronic disease management strategy is being developed by the Department of Health and Social Services, and a first draft of the document had been developed and was under review. SMS is recognized as an important component of the chronic disease management strategy and was included in the draft. The number of programs that fully integrate self-management is limited in the region; some diabetes education programs and a small number of other disease-specific pro- 
grams, such as mental health programs, have incorporated elements of self-management. A chronic disease management strategy will provide opportunities to enhance the role of self-management in these programs and design new programs that better address the need for SMS in the Northwest Territories.

\section{Yukon}

The Department of Health and Social Services has applied for funding to begin developing a chronic disease prevention and management strategy. According to the experts we interviewed, the aim is to include self-management in this strategy. The Stanford Chronic Disease SelfManagement Program is no longer being offered by the Department of Health and Social Services, largely due to difficulties in finding a sufficient number of interested patients. The Chronic Conditions Support Program is offered to both patients with chronic conditions and health professionals engaged in their care. The program is not primarily a self-management program, but does contain a few related components.

\section{Discussion}

Through our scan of environmental policies, we found that although most provinces and territories have policies that incorporate aspects of chronic disease selfmanagement, these policies were often embedded within other initiatives and/or policy documents framed around specific populations or diseases. The lack of specific self-management policies in all of Canada's North was surprising given that these regions have the highest burden of chronic diseases in the country. ${ }^{39,40}$ Residents also have many challenges in accessing care. Other competing health priorities, combined with the geographical spread of the population, may be reasons for self-management being under-developed here.

Great potential for improving health does exist in the North given that the most common and effective chronic disease selfmanagement programs ${ }^{15,41}$ are based on the peer support model that does not rely on access to trained health care professionals. In addition, many of the programs have already been adapted and success- fully implemented for many cultures and into different languages. ${ }^{42-44}$

Canada has many disease-focused strategies that incorporate self-management as a theme. For example, SMS programs in Ontario are mainly funded as part of the Ontario Diabetes Strategy. This diminishes the ability to integrate care on a programmatic level as performance measures are then often linked to specific diseases and not to the population. Although diabetes care is often framed as a first step or template in tackling chronic diseases, the self-management approaches in diabetes remain tethered to disease-specific medical management, such as content knowledge on diabetes and learning medical tasks (i.e. managing insulin). In addition, the population that is targeted by these SMS programs are people with diabetes, which tends to exclude groups of people with other chronic diseases.

It is critical to maintain focus on a more generic approach (dealing with fatigue, action planning for a healthy lifestyle, etc.) that addresses all three dimensions of self-management: patients medically managing their illness; carrying out normal roles and activities; and managing the emotional impact. ${ }^{15}$ Focusing on common risk factors across all chronic diseases is a basic principle of the Chronic Care Model approach. ${ }^{36}$ The World Health Organization recommends that "sound and explicit government policy is the key to effective prevention and control of chronic diseases." $45, \mathrm{p} 2$ A generic strategy that takes a life course perspective and is co-ordinated among decision makers across sectors is recommended. ${ }^{45}$

Alberta and British Columbia, the provinces that seem to have the most comprehensive self-management approaches, are also the ones with the most detailed policies/strategies that are not disease specific. Both feature primary health care and primary care prominently. The role of the primary care provider can be seen as foundational in supporting patient selfmanagement. The nature of primary care and its position within the health care system makes it a perfect target for such interventions. Primary care not only has access to most patients with chronic con- ditions but can also address different medical conditions beyond one specific disease. Primary care providers are in an ideal position to play a central role in preventing and managing chronic conditions, as $95 \%$ of Canadians with a chronic disease report having a regular family physician. ${ }^{46}$ Primary care visits provide a unique opportunity to monitor patients' health and to encourage self-management, ${ }^{47-49}$ as the majority of Canadians perceive their family physician to be a credible resource of health information and value their advice. ${ }^{50,51}$ As these provinces move forward with strategies grounded more in the primary health care community rather than disease areas, it will be important to evaluate the impact the different provincial policies have on program reach and overall effectiveness. To date, there is still very little published evidence that describes the overall reach of SMS programs in all provinces. ${ }^{52}$

Future research examining the association of policy and program reach and effect in self-management of chronic diseases is needed.

\section{Limitations}

The findings of this study are limited by several factors including participation bias and issues related to timing. We relied mainly on the initial contact list of jurisdictional representatives provided by the HCC. Although we did speak to representatives from all the provinces and territories and we did follow up for verification and/or clarification as needed, individual depth of knowledge varied, probably as a result of how much time they had spent in that position and their overall knowledge of the governmental system. These aspects were not specifically assessed.

In addition, a common limitation of policy scans relates to much of the material being time sensitive and linked to political agendas and public statements; thus, material was not necessarily publicly available when we were conducting our research. We attempted to minimize this limitation through interviewing the experts in the field as well as by conduct- 
ing an updated online scan after the interviews, in July 2012.

\section{Conclusion}

Evidence suggests that engaging patients in self-management of their chronic diseases is important and effective. Although most provinces and territories have policies that incorporate aspects of chronic disease self-management, these policies are often embedded within other initiatives and/or policy documents framed around specific diseases or populations. This approach could limit the potential reach and effect of self-management. Creating policies that identify self-management as a key element in a total population approach could lead to improved care for Canadians living with chronic diseases.

\section{Acknowledgements}

Funding for this report was provided by the Health Council of Canada as part of the development of a technical paper on chronic disease self-management. The authors would like to acknowledge the contributions of Mary Byrnes from the Health Council of Canada, who liaised with the jurisdictional representatives for the interviews, and Ottawa-based medical editor Joan Ramsay, who helped with the editorial development of this article.

\section{References}

1. The Secretariat for the Intersectoral Healthy Living Network; The F/P/T Healthy Living Task Group; The F/P/T Advisory Committee on Population Health and Health Security (ACPHHS). The Integrated Pan-Canadian Healthy Living Strategy. Ottawa (ON): Ministry of Health; 2005 [cited 2013 May 30]. Available from: http://www.phac-aspc.gc.ca/hl-vs-strat/pdf /hls_e.pdf

2. Integrated chronic disease preventionbuilding it together: a call to action. 2nd national conference of the Chronic Disease Prevention Alliance of Canada (CDPAC). 2006 Nov; Ottawa (ON). Ottawa (ON): Chronic Disease Prevention Alliance of Canada;[2006?; cited 2012 Nov 5] 3 p. Available from: http://www.cdpac.ca $/$ media.php?mid $=270$
3. Fortin M, Bravo G, Hudon C, et al. Relationship between multimorbidity and health-related quality of life of patients in primary care. Qual Life Res. 2006;15(1): 83-91.

4. Fortin M, Bravo G, Hudon C, Lapointe L, Dubois MF, Almirall J. Psychological distress and multimorbidity in primary care. Ann Fam Med. 2006;4(5):417-22.

5. Fortin M, Soubhi H, Hudon C, Bayliss EA, van den Akker M. Multimorbidity's many challenges. BMJ. 2007;334(7602):1016-7.

6. Hansagi H, Olsson M, Sjoberg S, Tomson Y, Goransson S. Frequent use of the hospital emergency department is indicative of high use of other health care services. Ann Emerg Med. 2001;37(6):561-7.

7. Incalzi RA, Capparella O, Gemma A, et al. The interaction between age and comorbidity contributes to predicting the mortality of geriatric patients in the acute-care hospital. J Intern Med. 1997;242(4):291-8.

8. Librero J, Peiro S, Ordinana R. Chronic comorbidity and outcomes of hospital care: length of stay, mortality, and readmission at 30 and 365 Days. J Clin Epidemiol. 1999;52(3):171-9.

9. Poses RM, McClish DK, Smith WR, Bekes C, Scott WE. Prediction of survival of critically ill patients by admission comorbidity. J Clin Epidemiol. 1996;49(7):743-7.

10. Rochon PA, Katz JN, Morrow LA, et al. Comorbid illness is associated with survival and length of hospital stay in patients with chronic disability. A prospective comparison of three comorbidity indices. Med Care. 1996;34(11):1093-101.

11. Committee on Quality of Health Care in America. Crossing the quality chasm: a new health system for the 21st century. Washington (DC): National Academies Press; 2001.

12. Anderson RM, Funnell MM, Butler PM, Arnold MS, Fitzgerald JT, Feste CC. Patient empowerment. Results of a randomized controlled trial. Diabetes Care. 1995;18(7): 943-9.

13. Vickery DM, Kalmer H, Lowry D, Constantine M, Wright E, Loren W. Effect of a self-care education program on medical visits. JAMA. 1983;250(21):2952-6.
14. Bodenheimer $\mathrm{T}$, Lorig $\mathrm{K}$, Holman $\mathrm{H}$, Grumbach K. Patient self-management of chronic disease in primary care. JAMA. 2002;288(19):2469-75.

15. Lorig KR, Holman HR. Self-management education: History, definitions, outcomes, and mechanisms. Annals of Behavioral Medicine. 2003;26(1):1.

16. McGowan P. The Chronic Disease SelfManagement Program in British Columbia. In: Dorland J, McColl MA, editors. Emerging approaches to chronic disease management in primary health care: managing chronic disease in the twenty-first century. Kingston (ON): Queen's University School of Policy; 2007. p. 79-90.

17. Newman S, Steed E, Mulligan K. Chronic physical illness: self-management and behavioural interventions. Maidenhead (UK): Open University Press; 2009.

18. Pearson ML, Mattke S, Shaw R, Ridgely S, Wiseman SH. Patient self-management support programs: an evaluation [Internet]. Agency for Healthcare Research and Quality, US Department of Health and Human Services; 2007 [cited 2012 Nov 5]. Available from: http://www.ahrq.gov /qual/ptmgmt/index.html\#contents

19. Wagner EH, Austin BT, Von Korff M. Organizing care for patients with chronic illness. Milbank Q. 1996;74(4):511-44.

20. Zwar N, Harris M, Griffiths R, et al. A systematic review of chronic disease management. Canberra (AU): Australian Primary Health Care Research Institute; 2006.

21. Adams K, Greiner AC, Corrigan JM, editors. Report of a summit. The 1st annual crossing the quality chasm summit - A focus on communities. Washington (DC): National Academies Press; 2004.

22. Johnston SE, Liddy CE, Ives SM. Selfmanagement support: a new approach still anchored in an old model of health care. Can J Public Health. 2011;102(1):68-72. 
23. Edwards P, Mawani A; The Alder Group for the Healthy Aging and Wellness Working Group of the Federal/Provincial/Territorial Committee of Officials (Seniors). Healthy aging in Canada: a new vision, a vital investment-a discussion brief. 3, Achieving the Vision. Ottawa (ON): Public Health Agency of Canada; 2013 [cited 2013 Apr 23]. Available from: http://www.phac -aspc.gc.ca/seniors-aines/publications/public /healthy-sante/vision/vision-bref/chap03-eng .php

24. Canadian Diabetes Strategy: history, evolution, moving forward [Internet]. Ottawa (ON): Public Health Agency of Canada; [modified 2013 Feb18; cited 2013 Apr 23]. Available from: http://www.phac-aspc.gc.ca/cd-mc /diabetes-diabete/strategy_funding-strategie _finance-eng.php?phac_source $=$ Diabetes homepage\&medium = featurebox\&campaign = Diabetes_feature

25. Health Council of Canada. Self-management support for Canadians with chronic health conditions: a focus for primary health care. Toronto (ON): Health Council of Canada; 2012 May.

26. Liddy CE, Johnston S, Mill K, Shahidi J. Self-management support interventions: technical paper on the sustainability of self-management supports for people with chronic conditions and the availability of self-management support programs for people with multiple chronic conditions. Unpublished document; [2011].

27. Broemeling AM, Watson DE, Prebtani F. Population patterns of chronic health conditions, co-morbidity and healthcare use in Canada: implications for policy and practice. Healthc Q. 2008;11(3):70-6.

28. Buse K, Mays N, Walt G. Making health policy. Maidenhead (UK): Open University Press; 2005.

29. Canadian Partnership Against Cancer. Environmental scan of policy and legislation as it relates to skin cancer prevention: executive summary. Winnipeg (MB): Primary Prevention Action Group; 2009 May.
30. Bergeron K. Ontario Heart Health Network: collaborative policy scan project - final report [Internet]. Toroto (ON): Ontario Heart Health Network; 2010 Mar [cited 2013 May 30]. Available from http://www.goforhealth .ca/Areas/Custom/ContentFiles/GFH \% 20 Resources/Full_OHHN_PolicyScan \%20march _2010.pdf

31. McGrath C, Myers J. Policies that Support Bridging, Bonding and Building Between Government and the Social Economy in Atlantic Canada: policy scan process report 2009. Halifax (NS): Social Economy and Sustainability Research Network; 2009.

32. Dixon-Woods M, Agarwal S, Jones D, Young B, Sutton A. Synthesising qualitative and quantitative evidence: a review of possible methods. J Health Serv Res Policy. 2005 Jan;10(1):45-53.

33. Vision 2020: The Future of Health Care in Alberta. Edmonton (AB): Alberta Health and Wellness; 2008.

34. Government of British Columbia. Primary Health Care Charter: a collaborative approach [Internet]. Victoria (BC): British Columbia Ministry of Health; 2012. Available from: http://www.health.gov .bc.ca/library/publications/year/2007/phc _charter.pdf

35. Barr VJ, Robinson S, Marin-Link B, et al. The expanded Chronic Care Model: an integration of concepts and strategies from population health promotion and the Chronic Care Model. Hosp Q. 2003; 7(1):73-82.

36. Wagner EH, Austin BT, Davis C, Hindmarsh M, Schaefer J, Bonomi A. Improving chronic illness care: translating evidence into action. Health Affairs. 2001;20(6):64-78.

37. Lemmens KM, Nieboer AP, van Schayck CP, Asin JD, Huijsman R. A model to evaluate quality and effectiveness of disease management. Qual Saf Health Care. 2008 Dec;17(6):447-53.
38. Improving health together: a policy framework for chronic disease prevention and management in Newfoundland and Labrador. St. John's (NL): Newfoundland and Labrador Department of Health and Community Services; 2011 Dec [cited 2012 Nov 5]. Available from: http://www.health .gov.nl.ca/health/chronicdisease/Improving _Health_Together.pdf

39. Bruce SG, Riediger ND, Zacharias JM, Young TK. Obesity and obesity-related comorbidities in a Canadian First Nation population. Prev Chronic Dis. 2011; 8(1):A03.

40. Aboriginal Diabetes Initiative. Diabetes among Aboriginal (First Nations, Inuit and Métis) people in Canada: the evidence. Ottawa (ON): Health Canada; 2001.

41. Brady TJ, Murphy L, Beauchesne D, et al. Sorting through the evidence for the Arthritis Self-Management Program and the Chronic Disease Self-Management Program: executive summary of ASMP/ CDSMP meta-analyses [Internet]. Atlanta (GA): Centers for Disease Control and Prevention;. 2011 May [cited 2012 Nov 5]. Joint publication of the Department of Health and Human Services, Washington (DC). Available from: www.cdc.gov/arthritis /docs/ASMP-executive-summary.pdf

42. Barceló A, Cafiero E, de Boer M, et al, Veracruz Project for the improvement of diabetes care (VIDA) - final report. Washington (DC): Pan American Health Organization; 2010.

43. Griffiths C, Motlib J, Azad A, et al. Randomised controlled trial of a lay-led selfmanagement programme for Bangladeshi patients with chronic disease. $\mathrm{Br} \mathrm{J}$ Gen Pract. 2005;55(520):831-7.

44. $\mathrm{Fu} \mathrm{D,} \mathrm{Fu} \mathrm{H,} \mathrm{McGowan} \mathrm{P}$, et al. Implementation and quantitative evaluation of chronic disease self-management programme in Shanghai, China: randomized controlled trial. Bull World Health Organ. 2003;81(3):174-82.

45. World Health Organization. Policy brief: preventing chronic diseases: designing and implementing effective policy [Internet]. Geneva $(\mathrm{CH})$ : World Health Organization; [cited 2013 May 30]. Available from: http://www.who.int/chp/advocacy/policy .brief_EN_web.pdf 
46. Glazier RH, Moineddin R, Agha M, et al. The Impact of not having a primary care physician among people with chronic conditions. ICES Investigative Report Toronto (ON): Institute for Clinical Evaluative Sciences; 2008 Jul.

47. Chan BT. The declining comprehensiveness of primary care. CMAJ. 2002;166(4):429-34.

48. Cifuentes M, Fernald DH, Green LA, et al. Prescription for health: changing primary care practice to foster healthy behaviors. Ann Fam Med. 2005;3 Suppl 2:S4-11.

49. Hensrud DD. Clinical preventive medicine in primary care: background and practice: Rationale and current preventive practices. Mayo Clin Proc. 2000;75(2):165-72.

50. Folsom AR, Grimm RH Jr. Stop smoking advice by physicians: a feasible approach? Am J Public Health. 1987;77(7):849-50.

51. Green LA, Fryer GE Jr., Yawn BP, Lanier D, Dovey SM. The ecology of medical care revisited. N Engl J Med. 2001;344(26): 2021-5.

52. Johnston S, Liddy $\mathrm{C}$, Mill $\mathrm{K}$, Irving $\mathrm{H}$. Building the evidence base for chronic disease self-management support interventions across Canada. Can J Public Health. 2012;103(6):e462-67. 